\title{
Left Ventricular Function in Acute Myocardial Infarction
}

\author{
Paul Hamosh and Jay N. Cohn \\ From the Hypertension and Clinical Hemodynamics Section, Veterans \\ Administration Hospital, Washington, D. C. 20422, and the Departments of \\ Medicine and Physiology, Georgetown University Medical Center, \\ Washington, D. C. 20007
}

A B S T R A C T Left ventricular catheterization was carried out in 40 patients with acute myocardial infarction. Left ventricular end-diastolic pressure (LVEDP) was elevated in $85 \%$ of the patients studied. In 14 patients with apparently uncomplicated infarcts, LVEDP averaged $15 \mathrm{~mm} \mathrm{Hg}$, and cardiac index (2.98 liter $\left./ \mathrm{min} / \mathrm{m}^{2}\right)$, stroke volume $\left(38.3 \mathrm{ml} / \mathrm{m}^{2}\right)$, and stroke work $(49.2$ $\mathrm{g}-\mathrm{m} / \mathrm{m}^{2}$ ) were within normal limits. In 12 patients with clinical signs of left ventricular failure, LVEDP averaged $29.9 \mathrm{~mm} \mathrm{Hg}$, cardiac index was at the lower limit of normal (2.79 liter $\left./ \mathrm{min} / \mathrm{m}^{2}\right)$, but stroke volume (31.6 $\left.\mathrm{ml} / \mathrm{m}^{2}\right)$ and stroke work $\left(37.3 \mathrm{~g}-\mathrm{m} / \mathrm{m}^{2}\right)$ were reduced. In 14 patients with clinical signs of shock, LVEDP averaged significantly lower than in the heart failure group $(21.1 \mathrm{~mm} \mathrm{Hg}$ ), but cardiac index (1.59 liter/min/ $\left.\mathrm{m}^{2}\right)$, stroke volume $\left(16.5 \mathrm{ml} / \mathrm{m}^{2}\right)$, and stroke work $(11.1$ $\mathrm{g}-\mathrm{m} / \mathrm{m}^{2}$ ) were markedly reduced. A large presystolic atrial "kick" (average amplitude $9.5 \mathrm{~mm} \mathrm{Hg}$ ) was an important factor in the high LVEDP in the patients with heart failure but not in those with shock. The first derivative of left ventricular pressure was significantly lower in shock than in the nonshock group. Although right atrial pressure (RAP) and LVEDP were significantly correlated $(r=0.49)$, wide discrepancies in individual patients rendered the RAP an unreliable indicator of the magnitude of left ventricular filling pressure.

These data show the following: (a) LVEDP is usually elevated in acute myocardial infarction, even in absence of clinical heart failure; $(b)$ cardiac output apparently is supported by increased LVEDP and compensatory tachycardia; $(c)$ in patients with shock, left ventricular function usually is markedly impaired, but inadequate compensatory cardiac dilatation or tachycardia could contribute to the reduced cardiac output in some indi-

This work was presented in part at the meeting of The American Society for Clinical Investigation, Inc., Atlantic City, N. J., 5 May 1969. (1969. J. Clin. Invest. 48: 33a.) Received for publication 10 July 1970 and in revised form 14 October 1970. viduals; $(d)$ lower LVEDP in shock than in heart failure may represent differences in left ventricular compliance.

\section{INTRODUCTION}

Evaluation of cardiac function during acute myocardial infarction has previously been limited to the assessment of clinical and radiological signs (1), the measurement of cardiac output (2-5), right heart and pulmonary artery pressures $(6,7)$, and external indices of cardiac performance $(8,9)$. Although these studies have provided some insight into the severity of cardiac impairment which may accompany myocardial infarction, more precise quantitation of left ventricular dysfunction requires the direct measurement of left ventricular pressures $(10$, 11).

In recent years the mortality rate from arrhythmias in myocardial infarction has been markedly reduced, but mortality from the complications of pump failure has not been significantly altered $(12,13)$. The need for improved management of cardiac and circulatory failure after myocardial infarction has led to the introduction of new drugs $(14,15)$, mechanical cardiac assist devices (16), and aggressive surgical procedures (17) for the emergency treatment of myocardial infarction. The availability of these techniques has increased the requirement for an understanding of the functional disturbance associated with acute myocardial infarction and of means for detecting early signs of impending pump failure (18).

The development of a bedside method for catheterization of the left ventricle (19) has made it possible to evaluate left ventricular function with minimal disturbance in patients with acute myocardial infarction. The purpose of the present report is to describe the results of these studies in 40 patients with acute myocardial infarction, including 12 with clinical signs of left heart failure and 14 with shock. 


\section{METHODS}

Subjects. Studies were performed in the Intensive Care Units of the Veterans Administration Hospital or Providence Hospital, Washington, D. C. Subjects studied were hospitalized with typical chest pain associated with electrocardiographic evidence of acute myocardial infarction. All were males except patients 9 and 14. All patients who survived over $24 \mathrm{hr}$ exhibited elevated serum levels of glutamic oxaloacetic transaminase (SGOT). Patients with atypical symptoms or nonspecific electrocardiograms were excluded. In 38 subjects the ECG showed loss of forces indicative of transmural myocardial infarction, while in the other two the changes were typical of subendocardial infarction. Autopsies performed in 12 of the patients, who expired, confirmed the diagnosis of acute myocardial infarction.

14 patients had signs of shock at the time of study. Left ventricular function studies in this group were initiated in January, 1966. Shock was diagnosed by a fall in auscultatory systolic pressure to less than $90 \mathrm{~mm} \mathrm{Hg}$ accompanied by one or more signs of inadequate peripheral blood flow, including oliguria (urine output less than $20 \mathrm{ml} / \mathrm{hr}$ ), dulled sensorium, cool and clammy skin, and lactic acidosis. These patients were studied as soon as possible after the diagnosis of shock was made. The interval from onset of the acute myocardial infarction to study ranged from $2 \mathrm{hr}$ to 36 days (Table II).

Studies in the 26 patients with acute myocardial infarction without shock were initiated in January, 1968. Patients were accepted for study only if the catheterization procedure could be accomplished within $24 \mathrm{hr}$ from the onset of symptoms of myocardial infarction. Although studies were performed on a number of patients with no apparent complications, a particular attempt was made to include patients who exhibited some clinical signs of acute heart failure. Therefore, the subjects of this study do not represent a randomly selected group but rather a sample weighed in favor of more complicated cases. Patients were excluded if they had evidence of iliofemoral arterial disease, preexisting severe chronic heart failure, or other medical diseases (except hypertension) which might affect cardiac function.

In subjects conforming with the above criteria, permission for catheterization was obtained from the patient and/or his family. The nature of the procedure and the possible complications were described in detail. Studies in nine patients were excluded either because the left ventricle could not be catheterized or because severe hypotension prevented measurements from being made in a control steady state free of vasoactive drug administration.

Most patients had been treated with narcotics and sedatives as indicated, and these were continued during the procedure if the clinical situation warranted their administration. Some of the patients had been on long-term digitalis therapy before their admission, and a few had been treated with a diuretic before study. Indicated drug therapy was not withheld from the patients in shock while preparations for study were being made. If a sympathomimetic amine had been administered, this was usually discontinued while the hemodynamic status was closely monitored. If blood pressure stabilized after the drug was stopped for at least 30 min, results at this time were used as control observations. If the drug could not be discontinued because of a potentially dangerous fall in blood pressure, therapy was promptly reinstituted, and data on the patient were not included in this analysis.

Procedures. The left ventricle was catheterized with a modified red Kifa catheter via the femoral artery using the
Seldinger technique (19). The right atrium was entered with a PE 160 catheter either through the femoral or antecubital veins. Pressures were measured with Statham P23Db and P23BB strain gage transducers amplified and recorded on multichannel direct-writing recorders (Hewlett-Packard or Waters). Left ventricular end-diastolic pressure (LVEDP) was calculated at the base of the rapid ventricular pressure rise or $0.05 \mathrm{sec}$ after the onset of the QRS deflection of the electrocardiogram. Left ventricular mean diastolic pressure was taken as the average diastolic pressure before atrial contraction. The maximum rate of rise of left ventricular pressure $(\mathrm{dp} / \mathrm{dt})$ was calculated from pressure waves recorded at $100 \mathrm{~mm} / \mathrm{sec}$ paper speed after the catheter was thoroughly flushed. Under ideal laboratory conditions the frequency response of the catheter and recording system was flat $\pm 5 \%$ to 15 cycles $/ \mathrm{sec}$.

Cardiac output was determined by the dye dilution method. Indocyanine green, $5 \mathrm{mg}$, was injected as a bolus into the right atrium while blood was withdrawn at a constant rate from the left ventricle or ascending aorta through a Gilford or Waters cuvette. Calculation was made from the dye curves by the standard Stewart-Hamilton method. Dye curves were obtained in duplicate or triplicate in most patients and were reproducible within $15 \%$. Cardiac output was measured in eight patients in the shock group. In three the urgent clinical situation prevented performance of more than one control dye curve. In four of the patients with shock, dye curves from the right atrium to left ventricle exhibited normal contour and exponential disappearance with total dye passage time averaging $34 \mathrm{sec}$. In three patients the dye curves were considerably prolonged (passage time ranged from 72 to $186 \mathrm{sec}$ ), and although an exponential decline could be plotted, early recirculation probably led to an underestimation of cardiac output (patients 32-34). Mean transit time and central blood volume were not calculated in the patient with the most prolonged curve. In one patient with very prolonged transit time from the right atrium to left ventricle, dye curves were recorded from the femoral artery after injection into the left ventricle. These curves exhibited rapid transit and excellent reproducibility.

Left ventricular stroke work (LVSW) in $\mathrm{g}-\mathrm{m} / \mathrm{m}^{2}$ was calculated from the formula:

$\frac{(\mathrm{MAP}-\mathrm{LVEDP}) \times \mathrm{SV} \times 13.6}{1000}$, where MAP is mean aortic pressure, and $\mathrm{SV}$ is stroke volume corrected for body surface area $\left(\mathrm{ml} / \mathrm{m}^{2}\right)$. Central blood volume $(\mathrm{CBV})$ in $\mathrm{ml} / \mathrm{m}^{2}$ was calculated from the formula: $\frac{\text { MTT } \times C I}{60}$, where MTT is the mean transit time from the right atrium to the left ventricle or ascending aorta, and CI is the cardiac index in liter $/ \mathrm{min}$ per $\mathrm{m}^{2}$. Systemic vascular resistance (SVR) in dyne $\cdot \mathrm{sec} \cdot \mathrm{cm}^{-5}$ was calculated from the formula: $\frac{(\text { MAP }- \text { RAP) } \times 1332 \times 60}{C O}$, where $\mathrm{RAP}$ is mean right atrial pressure in $\mathrm{mm} \mathrm{Hg} . \mathrm{PO}_{2}$ was measured by a Clark electrode and serum glutamic oxaloacetic transaminase (SGOT) was determined by the AutoAnalyzer.

Complications. Left ventricular catheterization was successful in over $80 \%$ of the attempts. Fluoroscopy was employed in the early cases, but the ease of passage of the catheter obviated the need for this aid. Failure was attributable in most cases to local atherosclerotic disease in the femoral and iliac arteries. Occasionally, the catheter would coil in the ascending aorta and fail to negotiate the aortic valve. 
The following complications, which may have been related to the procedure, were observed: (a) Ventricular tachycardia in one case occurred several minutes after the catheter had been withdrawn from the left ventricle into the ascending aorta. The arrhythmia was terminated electrically and did not recur. The patient was subsequently discharged from the hospital. In two other cases a short run of ventricular tachycardia occurred when the ventricle was entered, and the procedure was abandoned. One of these patients was found to be severely hypokalemic at the time of study (serum $\mathrm{K}=2.4 \mathrm{mEq} /$ liter). Ventricular irritability was almost never observed after the catheter was positioned in the left ventricular cavity. Premature beats were more often associated with the right heart catheter if it was in the area of the tricuspid valve. These could be controlled by withdrawing the venous catheter a few centimeters. (b) Atrial fibrillation occurred in one case during the procedure and spontaneously reverted to sinus rhythm the following day. (c) Cerebral embolization occurred in one patient $16 \mathrm{hr}$ after the procedure. The symptoms were mild hemiparesis and aphasia which cleared 2 days later. This patient succumbed to a second infarction on the 7th day of hospitalization, and the autopsy revealed large mural thrombi in the left ventricle. $(d)$ Chest pain occurred during the procedure in several patients, but the causal relationship to the catheterization cannot be determined since all patients were studied early in the course of myocardial infarction when chest pain is a common symptom.

\section{RESULTS}

Clinical data. 26 patients with acute myocardial infarction without clinical signs of shock are described in Table I (group 1). 14 patients with clinical signs of shock are described in Table II (group 2). The mean age of group 1 patients was $51.6 \mathrm{yr}$, and of group 2, $63.4 \mathrm{yr}(P<0.01)$. None had cardiac murmurs at the time of study suggestive of mitral regurgitation. The incidence of previous myocardial infarctions in group 1 was $15.4 \%$ and in group $2,35.7 \%$. A history of hypertension was obtained in $54 \%$ of the patients in group 1 but only $14.3 \%$ in group 2 . The mortality during hospitalization was $15.4 \%$ in group 1 and $85.7 \%$ in group 2 . The location of the infarct defined by electrocardiogram and the incidence of preexisting angina pectoris or diabetes mellitus were not significantly different in the two groups.

Group 1 patients were subdivided on the basis of clinical and roentgenographic signs into two groups. Group 1a (patients 1-14, Table I) exhibited no signs of left ventricular failure. The lungs were clear to auscultation, and chest X-ray revealed no definite evidence of congestion. Group 1b (patients 15-26) presented with clinical evidence of heart failure manifested by persistent rales usually accompanied by $\mathrm{X}$-ray evidence of pulmonary venous engorgement or interstitial edema. Several of these latter patients had no pulmonary symptoms, but most were aware of mild to moderate shortness of breath. A ventricular diastolic gallop was heard near the cardiac apex by at least two independent observers in all patients in group $1 \mathrm{~b}$ but only two patients in group 1a. All group 1a patients recovered and were subsequently discharged from the hospital, whereas $33 \%$ of the group $1 \mathrm{~b}$ patients succumbed during hospitalization. Of the four fatal cases, three had previous myocardial infarctions, and all four had a history of hypertension.

Serum transaminase (SGOT) was measured on admission and on successive days of hospitalization. In some patients who succumbed on the day of admission, only one or no blood samples were obtained. The peak SGOT value detected within the first $72 \mathrm{hr}$ after onset of symptoms averaged $145 \mathrm{U}$ (range 60-339) in group 1a, $186 \mathrm{U}$ (range 100-360) in group $1 \mathrm{~b}$, and $532 \mathrm{U}$ (range 15-2660) in group 2. SGOT returned to normal before the end of the 1st wk in all uncomplicated cases.

Hemodynamic studies. The hemodynamic data are presented in Tables III and IV for groups 1 and 2, respectively. The mean and standard deviation are indicated for group 1 and subgroups $1 \mathrm{a}$ and $1 \mathrm{~b}$ in Table III and for group 2 in Table IV. The $t$ values and probability $(P)$ are shown in Table $\mathrm{V}$ and relevant correlation coefficients in Table VI.

Left ventricular end diastolic pressure (LVEDP) ranged from 6 to $40 \mathrm{~mm} \mathrm{Hg}$ in group 1 and from 8 to $34 \mathrm{~mm} \mathrm{Hg}$ in group 2. LVEDP was elevated (over 12 $\mathrm{mm} \mathrm{Hg})(20)$ in 10 of the 14 patients in group 1a who had no clinical signs of left ventricular failure. In group 1b LVEDP averaged $29.9 \mathrm{~mm} \mathrm{Hg}$ and was higher than in group 1a (average $15.0 \mathrm{~mm} \mathrm{Hg}$ ) and also higher than in the shock group (average $21.1 \mathrm{~mm} \mathrm{Hg}$ ). Two of the four group 1a patients with normal LVEDP (patients 4 and 6) exhibited electrocardiographic evidence of subendocardial rather than transmural infarction. LVEDP was also normal in two group 2 patients, including one with a right ventricular infarction confirmed by autopsy. Left ventricular mean diastolic pressure (LVMDP) was significantly lower than LVEDP in group 1b (average difference $9.5 \mathrm{~mm} \mathrm{Hg}$ ), because of a significant atrial "kick." In group 1a LVEDP averaged only $3.6 \mathrm{~mm} \mathrm{Hg}$ higher than LVMDP, and in the shock group the difference was only $2.9 \mathrm{~mm} \mathrm{Hg}$ (Fig. 1). The magnitude of the atrial "kick" was significantly greater in group $1 \mathrm{~b}$ than in the other groups $(P<0.05)$.

Mean right atrial pressure (RAP) was over $6 \mathrm{~mm} \mathrm{Hg}$ in 10 of the 14 patients in group 1a, all of the patients in group $1 \mathrm{~b}$, and 10 of the 14 patients in shock. RAP was significantly higher in group $1 \mathrm{~b}$ than in group 1a. RAP and LVEDP correlated better in shock $(r=0.625)$ than in the nonshock patients $(r=0.460)$ (Fig. 2). In three patients a normal RAP was associated with a normal LVEDP, but in the other five subjects, normal RAP coexisted with a modestly elevated LVEDP. In only two patients, (Nos. 7 and 39) was RAP higher than LVEDP. Both of these patients had electrocardiographic evidence 
of diaphragmatic infarction, and patient 7 also had preexisting lung disease. Postmortem examination of patient 39 revealed extensive infarction of the right ventricle.

Cardiac output was measured in 16 group 1 patients and 8 group 2 patients. In 14 patients in group 1, cardiac index $(\mathrm{CI})$ was over $2.5 \mathrm{liter} / \mathrm{min}$ per $\mathrm{m}^{2}$, whereas in group 2 only one patient had a CI in excess of 2.5 liter/ min per $\mathrm{m}^{2}$. Despite the clinical signs of heart failure, CI was not significantly lower in group $1 \mathrm{~b}$ patients than in the uncomplicated group 1a patients. LVEDP did not correlate significantly with CI in group 1 , but a significant negative correlation was observed in group $2(r=$ - 0.81) (Fig. 3). Group 1b patients exhibited significantly faster heart rates than group 1a, but no significant difference between groups 1 and 2 was observed. A low but significantly positive correlation coefficient was noted between LVEDP and heart rate in group $1(r=0.41)$, but in the shock group the correlation tended to be nega- tive $(r=-0.30)$. Despite the significant differences in RAP and LVEDP between the groups, calculated central blood volume (CBV) was practically identical for each group.

Stroke volume index (SV) was within the normal range $\left(38.8 \mathrm{ml} / \mathrm{m}^{2}\right)$ in group $1 \mathrm{a}$, but was moderately reduced in group $1 \mathrm{~b}\left(26.3 \mathrm{ml} / \mathrm{m}^{2}\right)$ and markedly reduced in shock $\left(16.5 \mathrm{ml} / \mathrm{m}^{2}\right)$. The differences between each group were significant. A significant negative correlation was observed between LVEDP and SV in group 1 $(r=-0.52)$, and group $2(r=-0.66)$. LVSW also fell progressively from group 1a to group 2. LVEDP and LVSW also correlated significantly in group 1 $(r=-0.68)$ and group $2(r=-0.62)$. The scatter (Fig. 4) shows little overlap between the groups.

The first derivative of left ventricular pressure $(\mathrm{dp} / \mathrm{dt})$ was significantly lower in group 2 than in group 1 , and the $\mathrm{dp} / \mathrm{dt}$ was directly correlated with LVEDP $(r=$ $0.60)$. However, absolute values for $\mathrm{dp} / \mathrm{dt}$ obtained

TABLE I

Clinical Data from Group 1 Patients (Nonshock)

\begin{tabular}{|c|c|c|c|c|c|c|c|c|}
\hline Patient & Age & BSA & Hypertension & Diabetes & $\begin{array}{l}\text { Previous } \\
\text { myocardial } \\
\text { infarction }\end{array}$ & $\begin{array}{l}\text { Angina } \\
\text { pectoris }\end{array}$ & $\begin{array}{l}\text { Location } \\
\text { of } \\
\text { myocardial } \\
\text { infarction }\end{array}$ & Mortality \\
\hline & & $m^{2}$ & & & & & & \\
\hline 1 & 38 & 2.02 & & & & & $\mathbf{P}$ & \\
\hline 2 & 56 & 1.83 & & & & & A & \\
\hline 3 & 45 & 1.87 & & & & & $\mathbf{P}$ & \\
\hline 4 & 51 & 1.90 & + & & & & $\mathbf{P}$ & \\
\hline 5 & 33 & 2.13 & + & & & & $\mathbf{P}$ & \\
\hline 6 & 39 & 2.02 & & & & & A & \\
\hline 7 & 54 & 1.79 & & & & & $P$ & \\
\hline 8 & 43 & 1.90 & & & & & $\mathbf{P}$ & \\
\hline 9 & 36 & 1.73 & + & & & + & $\mathrm{P}$ & \\
\hline 10 & 45 & 1.77 & & & & & A & \\
\hline 11 & 47 & 1.84 & & + & & + & A & \\
\hline 12 & 49 & 1.94 & & & & & A & \\
\hline 13 & 50 & 2.42 & + & + & & & $\mathrm{P}$ & \\
\hline 14 & 46 & 1.47 & & & & & A & \\
\hline 15 & 48 & 1.80 & & & & & $\mathbf{P}$ & \\
\hline 16 & 73 & 2.06 & + & & & + & $\mathbf{P}$ & + \\
\hline 17 & 53 & 2.18 & + & & & & A & + \\
\hline 18 & 60 & 1.80 & & & & + & A & \\
\hline 19 & 49 & 2.11 & + & + & + & + & A & \\
\hline 20 & 55 & 2.12 & + & + & + & + & A & + \\
\hline 21 & 50 & 1.98 & & & + & + & I & \\
\hline 22 & 73 & 1.68 & + & & + & + & $\mathrm{P}$ & + \\
\hline 23 & 44 & 1.88 & + & & & & $\mathrm{P}$ & \\
\hline 24 & 59 & 1.75 & + & & & + & $\mathrm{P}$ & \\
\hline 25 & 51 & 1.90 & & & & & A & \\
\hline 26 & 75 & 1.59 & + & & & + & A & \\
\hline
\end{tabular}

$\mathrm{BSA}=$ body surface area; $\mathrm{A}=$ anterior wall myocardial infarction; $\mathrm{I}=$ indeterminate location; $\mathrm{P}=$ posterior or diaphragmatic wall infarction. 
TABLE II

Clinical Data from Group 2 Patients (Shock)

\begin{tabular}{|c|c|c|c|c|c|c|c|c|c|}
\hline Patient & Age & BSA & $\begin{array}{l}\text { Time from } \\
\text { onset }\end{array}$ & $\begin{array}{l}\text { Hyper- } \\
\text { tension }\end{array}$ & Diabetes & $\begin{array}{l}\text { Previous } \\
\text { myocardial } \\
\text { infarction }\end{array}$ & $\begin{array}{l}\text { Angina } \\
\text { pectoris }\end{array}$ & $\begin{array}{l}\text { Location } \\
\text { of } \\
\text { myocardia } \\
\text { infarction }\end{array}$ & Mortality \\
\hline & & $m^{2}$ & $h r$ & & & & & & \\
\hline 27 & 54 & 1.88 & 11 & & & & + & A & + \\
\hline 28 & 71 & 1.97 & 76 & & + & & & I & + \\
\hline 29 & 66 & 1.97 & 2 & + & & + & & $\mathbf{P}$ & \\
\hline 30 & 54 & 1.59 & 12 & & & & + & I & + \\
\hline 31 & 53 & 1.78 & 120 & & + & + & + & A & + \\
\hline 32 & 61 & 1.80 & 48 & + & & + & + & A & + \\
\hline 33 & 72 & 1.51 & 36 days & & & $?$ & + & A & + \\
\hline 34 & 79 & 1.86 & 72 & & & + & + & $\mathbf{P}$ & + \\
\hline 35 & 61 & 2.03 & 72 & & + & + & + & $\mathbf{P}$ & + \\
\hline 36 & 60 & 1.59 & 7 days & & & & + & A & + \\
\hline 37 & 72 & 2.04 & 24 & & & & & & + \\
\hline 38 & 58 & 1.60 & 12 & & & & & & \\
\hline 39 & 63 & 1.85 & 10 days & & & & & $\mathbf{P}$ & + \\
\hline 40 & 64 & 1.59 & 72 & & & & + & A & + \\
\hline
\end{tabular}

Abbreviations same as in Table I.

through this catheter system should be interpreted with caution, and comparison between patients may be unreliable.

Systemic vascular resistance (SVR) tended to be normal in group 1 patients but was often elevated in shock; however, the wide scatter of values in the group 2 patients prevented this difference from reaching statistical significance.

Arterial oxygen tension $\left(\mathrm{PO}_{2}\right)$ was measured only in those patients to whom $\mathrm{O}_{2}$ was not administered or in whom it was elected to interrupt oxygen therapy. Oxygen administration was not discontinued in any of the group 2 patients. $\mathrm{PO}_{2}$ was inversely correlated with LVEDP in the nonshock patients, being significantly higher in group 1a than in group $1 \mathrm{~b}(r=-0.59)$ (Fig. $5)$.

\section{DISCUSSION}

The data obtained in the present study reveal that a disturbance in left ventricular function within the first 24 hr after an acute myocardial infarction is considerably more frequent than previous clinical observations have implied (21-23). Only 4 of 26 patients without shock had a normal LVEDP, and two of these had electrocardiographic evidence of subendocardial rather than transmural infarction. Not only was LVEDP frequently elevated in the absence of signs of left ventricular failure, but patients with only mild signs or symptoms of pulmonary congestion sometimes exhibited elevations in LVEDP to levels usually thought to be associated with significant pulmonary capillary transudation. Only one of seven patients with LVEDP from 25 to $40 \mathrm{~mm} \mathrm{Hg}$ had clinical signs of pulmonary edema at the time of study.

It must be recognized that a high LVEDP does not necessarily signify left ventricular dilatation (24). Since angina (25) and experimental myocardial infarction (26) have been thought to produce changes in compliance, the elevated LVEDP in some of the patients in this series could be related to decreased distensibility of the ventricles during diastole. Such a reduction in compliance might help to explain the observation that the central blood volumes showed no correlation with LVEDP or signs of heart failure. These central blood volume measurements were calculated from mean transit times from the right atrium to the left ventricle or ascending aorta and, therefore, represent exclusively cardiac and pulmonary blood volume. If the ventricle were operating on a very steep pressure volume curve, increments in ventricular volume too small to be detected by this method could account for the elevated LVEDP. The pulmonary vascular bed also may be nondistensible in left heart failure $(27,28)$, and thus pulmonary blood volume might not be much larger in patients with higher LVEDP. Since the LVEDP was elevated in nearly all the patients in this series, it is possible that the pulmonary blood volume was uniformly expanded and, therefore, bore no relationship to the absolute level of the LVEDP. 
Although a high LVEDP may not necessarily indicate left heart failure, patients with LVEDP over $19 \mathrm{~mm}$ $\mathrm{Hg}$ nearly always exhibited clinical or radiological signs of pulmonary congestion. LVEDP averaged $29.9 \mathrm{~mm} \mathrm{Hg}$ in the patients with clinically diagnosed left ventricular failure compared with an average of $15.0 \mathrm{~mm} \mathrm{Hg}$ in the patients without signs of heart failure. Cardiac index was not different in the two groups, but the heart rate was significantly faster and the stroke volume and stroke work lower in the patients with heart failure. Therefore, an increase in LVEDP and tachycardia apparently represent compensatory mechanisms by which cardiac output is maintained after severe myocardial infarction. A positive inotropic effect of reflex sympathoadrenal activation may also play a role in supporting cardiac performance (29). These observations suggest that the patients with clinical signs of heart failure had more severe impairment of left ventricular performance, but the data do not permit conclusions as to whether the cardiac dysfunction is due to: $(a)$ a larger noncontracting area of myocardium; (b) paradoxical pulsations (dyskenesia) of the infarcted area; or (c) failure of the uninvolved myocardium to adequately compensate by increased fiber shortening (30).

Although cardiac output is usually markedly reduced in patients with myocardial infarction shock, the central

TABLE III

Hemodynamic Data for Group 1 Patients

\begin{tabular}{|c|c|c|c|c|c|c|c|c|c|c|c|}
\hline Patient & MAP & LVEDP & LVMDP & RAP & CI & HR & SV & LVSW & $\mathrm{dp} / \mathrm{dt}$ & CBV & SVR \\
\hline & $m m H g$ & $m m H_{g}$ & $m m H g$ & $m m \mathrm{Hg}$ & $\begin{array}{c}\text { liter } / \min \\
\text { per } m^{2}\end{array}$ & beats/min & $\begin{array}{c}m l / \text { beats } \\
\text { per } m^{2}\end{array}$ & $g-m / m^{2}$ & & $m l / m^{2}$ & $\begin{array}{c}\text { dynes.sec } \\
\cdot \mathrm{cm}^{-5}\end{array}$ \\
\hline \multicolumn{12}{|l|}{ Group 1a } \\
\hline 1 & 96 & 15.0 & 12 & 4 & & 62 & & & 1360 & & \\
\hline 2 & 124 & 18.5 & 8 & 8 & 2.54 & 90 & 28.2 & 40.5 & 2608 & 641 & 2094 \\
\hline 3 & 87 & 13.0 & 9 & 4 & & 75 & & & 2070 & & \\
\hline 4 & 116 & 10.0 & 8 & 4 & & 67 & & & 1960 & & \\
\hline 5 & 120 & 17.0 & 12 & 12 & 3.45 & 88 & 39.1 & 54.7 & 2496 & 601 & 1177 \\
\hline 6 & 102 & 7.5 & 6 & 4 & 3.60 & 68 & 52.9 & 68.0 & 2556 & 593 & 1078 \\
\hline 7 & 83 & 6.0 & 6 & 12 & & 66 & & & & & \\
\hline 8 & 76 & 13.5 & 12 & 10 & & 78 & & & & & \\
\hline 9 & 75 & 16.5 & 13 & 10 & 2.70 & 56 & 48.1 & 38.3 & 1530 & 669 & 1115 \\
\hline 10 & 94 & 12.0 & 10 & 9 & 2.94 & 72 & 40.9 & 45.6 & 2240 & 487 & 1305 \\
\hline 11 & 135 & 18.5 & 15 & 7 & 2.85 & 95 & 30.0 & 47.5 & 2258 & 660 & 1954 \\
\hline 12 & 73 & 22.5 & 16 & 16 & & 64 & & & 2176 & & \\
\hline 13 & 98 & 20.5 & 18 & 12 & & 120 & & & 1320 & & \\
\hline 14 & 145 & 20.0 & 15 & 12 & 2.81 & 96 & 29.2 & 49.6 & 2023 & 831 & 2432 \\
\hline Mean & 101.7 & 15.0 & 11.4 & 8.8 & 2.98 & 78.4 & 38.3 & 49.2 & 2050 & 640.3 & 1590 \\
\hline $\mathbf{S D} \pm$ & 23.0 & 5.0 & 3.8 & 3.8 & 0.39 & 17.5 & 9.8 & 10.0 & 440 & 104 & 533 \\
\hline \multicolumn{12}{|l|}{ Group 1b } \\
\hline 15 & 73 & 32.0 & 21 & 7 & & 95 & & & 1590 & & \\
\hline 16 & 100 & 19.0 & 10 & 12 & 2.59 & 114 & 22.8 & 25.1 & 2480 & 531 & 1317 \\
\hline 17 & 99 & 38.5 & 22 & 9 & 2.90 & 104 & 27.9 & 23.0 & 1965 & 685 & 1124 \\
\hline 18 & 112 & 20.0 & 19 & 11 & 3.06 & 96 & 31.8 & 39.8 & 1597 & 635 & 1352 \\
\hline 19 & 84 & 34.0 & 12 & 11 & 2.72 & 116 & 23.4 & 15.9 & 1480 & 606 & 1087 \\
\hline 20 & 130 & 42.0 & 32 & 17 & & 86 & & & & & \\
\hline 21 & 99 & 22.0 & 19 & 9 & & 78 & & & & & \\
\hline 22 & 116. & 29.0 & 20 & 12 & 2.54 & 104 & 24.4 & 28.9 & 1824 & 750 & 1993 \\
\hline 23 & 104 & 35.0 & 26 & 11 & 3.38 & 128 & 26.4 & 24.8 & & 659 & 1169 \\
\hline 24 & 96 & 24.0 & 18 & 13 & 2.29 & 75 & 30.6 & 30.0 & 2000 & 498 & 1651 \\
\hline 25 & 128 & 40.0 & 30 & 12 & 2.78 & 81 & 34.4 & 41.2 & 2250 & 921 & 1750 \\
\hline 26 & 136 & 23.0 & 16 & 16 & 1.42 & 95 & 15.0 & 23.1 & 1520 & 476 & 4230 \\
\hline Mean & 106.4 & 29.9 & 20.4 & 11.7 & 2.63 & 97.7 & 26.3 & 28.0 & 1870 & 640.1 & 1740 \\
\hline SD士 & 18.8 & 8.2 & 6.5 & 2.8 & 0.55 & 16.3 & 5.8 & 8.2 & 350 & 138.6 & 983 \\
\hline \multicolumn{12}{|c|}{ Group 1 ( $a$ and $b$ ) } \\
\hline Mean & 103.9 & 21.9 & 15.6 & 10.1 & 2.79 & 87.3 & 31.6 & 37.3 & 1960 & 640.2 & 1680 \\
\hline SD士 & 20.9 & 10.0 & 6.9 & 3.6 & 0.51 & 19.3 & 9.7 & 13.9 & 410 & 120.7 & 802 \\
\hline
\end{tabular}


TABLE IV

Hemodynamic Data from Group 2 Patients

\begin{tabular}{|c|c|c|c|c|c|c|c|c|c|c|c|}
\hline Patient & MAP & LVEDP & LVMDP & RAP & CI & HR & SV & LVsw & $\mathrm{dp} / \mathrm{dt}$ & CBV & SVR \\
\hline & $m m \mathrm{Hg}$ & $m m H g$ & $m m \mathrm{Hg}$ & $m m \mathrm{Hg}$ & $\begin{array}{c}\text { liler } / \min \\
\text { per } m^{2}\end{array}$ & beats/min & $\begin{array}{c}\text { ml/beats } \\
\text { per } m^{2}\end{array}$ & $g-m / m^{2}$ & & $m l / m^{2}$ & $\begin{array}{c}\text { dyne } \cdot \mathrm{sec} \\
\cdot \mathrm{cm}^{-6}\end{array}$ \\
\hline 27 & 57 & 33 & 33 & 25 & & 80 & & & 564 & & \\
\hline 28 & 67 & 18 & 16 & 6 & & 90 & & & & & \\
\hline 29 & 70 & 34 & 27 & 18 & & 102 & & & & & \\
\hline 30 & 74 & 24 & 16 & 14 & & 90 & & & 1280 & & \\
\hline 31 & 76 & 30 & 26 & 14 & & 96 & & & 1080 & & \\
\hline 32 & 98 & 14 & 10 & 3 & 0.99 & 126 & 7.8 & 8.9 & 1320 & 810 & 4245 \\
\hline 33 & 92 & 30 & 24 & 12 & 0.58 & 74 & 7.8 & 6.6 & 960 & & 7356 \\
\hline 34 & 54 & 24 & 24 & 5 & 0.98 & 120 & 8.2 & 3.3 & 448 & 607 & 2579 \\
\hline 35 & 60 & 22 & 22 & 11 & 1.71 & 75 & 22.8 & 11.8 & 1280 & 543 & 1123 \\
\hline 36 & 86 & 16 & 11 & 8 & 2.07 & 108 & 19.1 & 18.2 & 1700 & 697 & 1897 \\
\hline 37 & 66 & 17 & 17 & 8 & 1.48 & 114 & 13.0 & 8.7 & 840 & 506 & 1537 \\
\hline 38 & 70 & 8 & 5 & 6 & 2.68 & 108 & 24.8 & 20.1 & 2880 & & 1196 \\
\hline 39 & 36. & 8 & 8 & 14 & 2.25 & 78 & 28.8 & 11.0 & 1280 & & 586 \\
\hline 40 & 70 & 18 & 16 & 13 & & 116 & & & 540 & & \\
\hline Mean & 69.7 & 21.1 & 18.2 & 11.2 & 1.59 & 98.4 & 16.5 & 11.1 & 1180 & 637.4 & 2560 \\
\hline sD \pm & 15.9 & 8.5 & 8.1 & 5.9 & 0.72 & 17.6 & 8.4 & 5.7 & 650 & 102.5 & 2241 \\
\hline
\end{tabular}

venous pressure is not always elevated $(2,13,14,31-33)$. Therefore, it has not been clear whether shock represents a particularly severe degree of left ventricular failure or the sequelae of some other hemodynamic abnormality. In the present series of patients with shock a profound reduction of cardiac output, stroke volume and stroke work was usually accompanied by an elevated LVEDP indicative of severe impairment of cardiac function. Since all these indices of cardiac performance were inversely correlated with LVEDP in the shock group, it is apparent that the level of the LVEDP serves as a useful guide to the severity of pump failure in shock.

No data are available to quantitate either infarct size or ventricular contractility in these patients. The rise in SGOT can serve as only a rough guide to the extent of myocardial necrosis because of the random timing of sample collection and the transaminase contribution from other sources when there is circulatory congestion or shock. Although the rate of pressure generation by the left ventricle is a sensitive guide to its contractile force (34), the maximum $\mathrm{dp} / \mathrm{dt}$ measured through a catheter system might yield unreliable results because of its limited frequency response. Furthermore, $\mathrm{dp} / \mathrm{dt}$ is influenced by the level of LVEDP, the aortic pressure, and the heart rate (35). Nonetheless, the significantly lower $\mathrm{dp} / \mathrm{dt}$ in the shock group when compared with the group 1 patients and the close negative correlation between LVEDP and $\mathrm{dp} / \mathrm{dt}$ in shock is at least consistent with the other evidence suggesting that shock usually is characterized by a more severe degree of left ventricular failure. Whether these signs of ventricular dysfunction represent the direct consequences of an extensive myocardial infarction or the secondary effects of the shock on ventricular performance cannot be ascertained.

Despite the evidence for severe myocardial impairment in most patients with shock, two subjects with mild signs of shock exhibited a normal LVEDP, and the average LVEDP in the shock group was significantly lower than in the patients with heart failure who were maintaining apparently normal peripheral circulation. Thus, it is possible that inadequate left ventricular dilatation, perhaps related to reduced venous return, was a contributing factor to the reduction in cardiac output in

TABLE V

Significance of Differences in Hemodynamic Measurements between Patient Groups $(P)$

\begin{tabular}{lccccccccccc}
\hline Group & MAP & LVEDP & LVMDP & RAP & CI & HR & SV & LVSW & dp/dt & CBV & SVR \\
\hline 1 vs. 2 & $<0.001$ & NS & NS & NS & $<0.001$ & $<0.1$ & 0.001 & $<0.001$ & $<0.001$ & NS & $<0.02$ \\
1a vs. 1b & NS & $<0.001$ & $<0.001$ & $<0.05$ & NS & $<0.01$ & $<0.01$ & $<0.001$ & NS & NS & NS \\
1b vs. 2 & $<0.001$ & $<0.02$ & NS & NS & $<0.01$ & NS & $<0.02$ & $<0.001$ & $<0.02$ & NS & NS \\
\hline
\end{tabular}


TABLE VI

Correlation Coefficients between LVEDP and Selected Hemodynamic Measurements

\begin{tabular}{lccc}
\hline & \multicolumn{3}{c}{ Group } \\
\cline { 2 - 4 } & 1 & 2 & $1+2$ \\
\hline RAP & +0.46 & +0.62 & +0.49 \\
CI & -0.15 & -0.81 & -0.03 \\
HR & +0.41 & -0.30 & +0.21 \\
SV & -0.52 & -0.66 & -0.24 \\
LVSW & -0.68 & -0.62 & -0.19 \\
dp/dt & -0.24 & -0.66 & -0.31 \\
\hline
\end{tabular}

some of these patients. Previous studies have demonstrated that some patients with myocardial infarction shock improve after plasma volume expansion (36-39).

Another possible explanation for the lower LVEDP in shock when compared with the heart failure group is a relatively increased ventricular compliance in shock. In the group with heart failure atrial contraction was associated with a prominent presystolic rise in left ventricular pressure averaging $9.5 \mathrm{~mm} \mathrm{Hg}$, whereas in the shock group the atrial "kick" was significantly smaller although the mean ventricular diastolic pressures before atrial systole were similar. It is possible that the absence of a significant atrial "kick" in shock merely reflects a smaller atrial stroke volume, but the findings also could be explained by differences in ventricular compliance. Either the infarcted left ventricle may be relatively non-

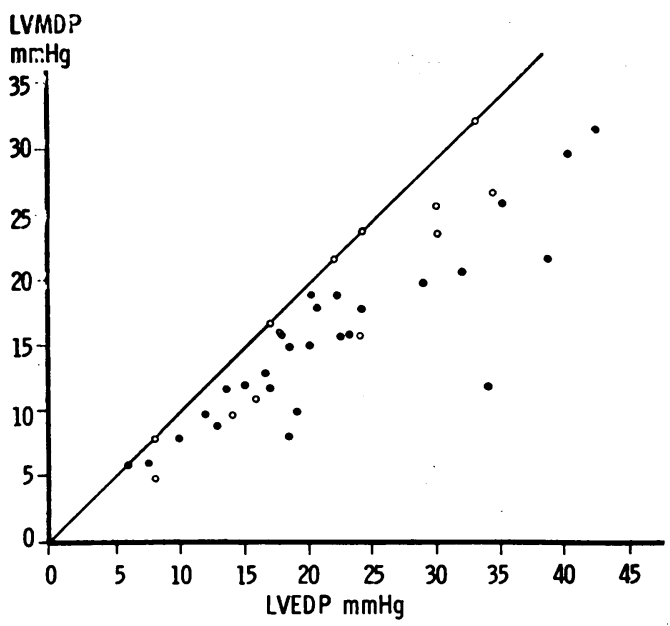

Figure 1 The relationship between left ventricular enddiastolic pressure (LVEDP) and left ventricular mean diastolic pressure (LVMDP). The closed circles represent patients from group 1, the open circles patients from group 2. The diagonal line represents the line of identity. At higher pressures patients with shock exhibit a smaller difference between LVMDP and LVEDP than in the nonshock group.

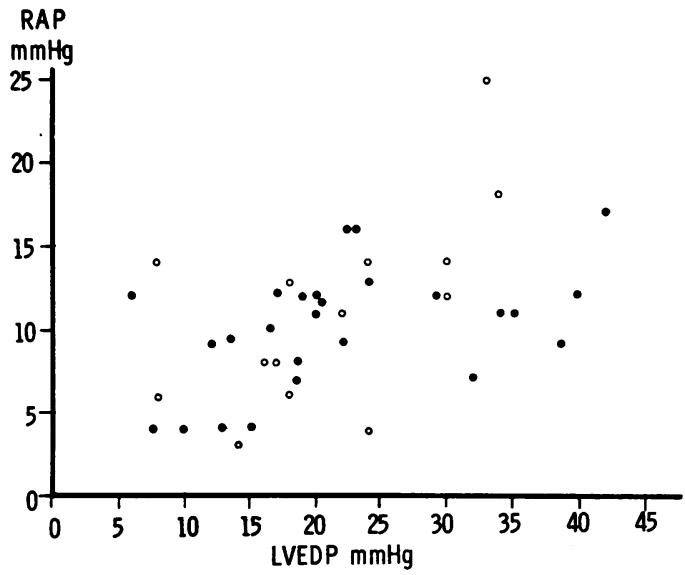

FIGURE 2 The relationship between left ventricular enddiastolic pressure (LVEDP) and right atrial pressure (RAP). Symbols same as in Fig. 1. Although correlation is significant $(r=0.49)$, a wide scatter is observed.

compliant in the absence of shock, or shock is associated with increased compliance due to generalized myocardial hypoxia or to large dyskinetic segments of the myocardium (35). The results also might have been influenced by the fact that nine of the patients with shock were studied more than $24 \mathrm{hr}$ after the onset of their myocardial infarction, whereas the nonshock group all were studied in the first day.

In several respects the shock group did not exhibit a homogenous hemodynamic pattern. Tachycardia, which appeared to be a predictable compensatory mechanism in the nonshock group with reduced stroke volume, was not uniformly present in shock. Indeed, heart rate tended to be negatively correlated with LVEDP in shock, and the low cardiac output in some patients could be at-

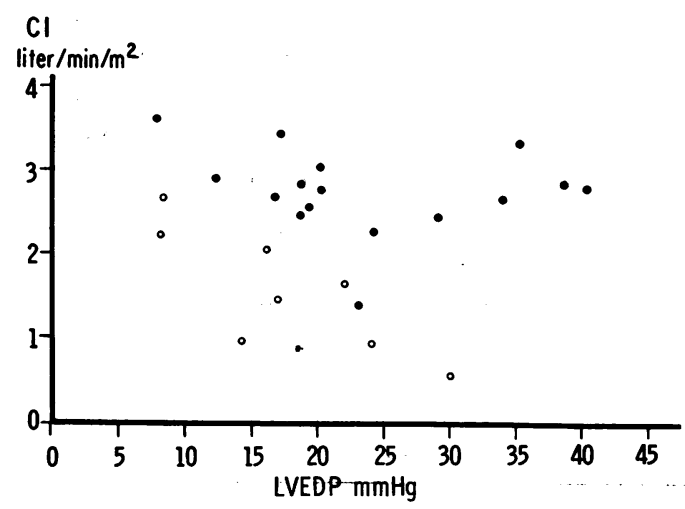

FIgURE 3 The relationship between left ventricular enddiastolic pressure (LVEDP) and cardiac index (CI). Symbols same as in Fig. 1. CI is maintained at normal levels in group 1 despite elevated LVEDP, whereas CI is inversely related to LVEDP in the shock group $(r=-0.81)$. 
tributed in part to the failure of the heart to increase its rate appropriately. However, the persistence of a slow heart rate in the face of a falling stroke volume in shock may represent an intrinsic protective device by which the ischemic heart defends itself against a tachycardia-induced increase in oxygen demand (40).

An increase in peripheral resistance, which might be expected as a compensatory response to a fall in cardiac output, was not uniformly present in the hypotensive patients with shock. Although vasoconstriction may have occurred in some vascular beds in these patients, the fact that total calculated resistance did not rise in all patients suggests that large vascular beds either failed to constrict or were actually dilated. Whether this failure of peripheral resistance to increase in some patients is an important pathogenetic factor in the shock (41), or merely represents a natural variation in the intensity of sympathetic reflex vasoconstrictor activity (42) cannot be determined. However, since heart rate and peripheral resistance both may fail to react appropriately in shock, it is possible that acidosis (43) or cerebral hypoxia (44) may be responsible for inhibiting normal cardiovascular reactivity.

The reliability of right atrial or central venous pressure (CVP) as an index of the severity of left ventricular failure in myocardial infarction is a subject of considerable clinical importance. RAP was elevated in 29 of the 34 patients with abnormal LVEDP in this series, and RAP was elevated in all but one patient with an LVEDP over $19 \mathrm{~mm} \mathrm{Hg}$. However, the correlation between RAP and LVEDP was not close $(r=0.495)$. In two patients the right atrial pressure was higher than the LVEDP, whereas in the others LVEDP surpassed RAP by from 2 to $29.5 \mathrm{~mm} \mathrm{Hg}$. Therefore, the absolute level

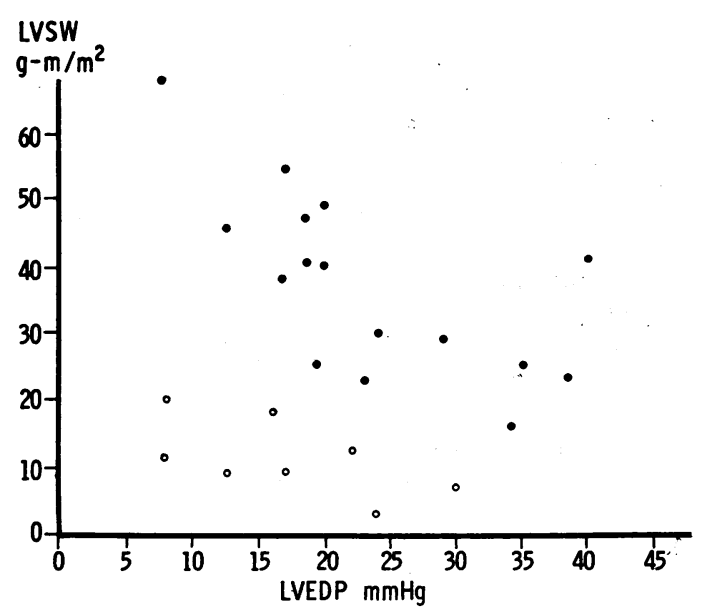

FIgURE 4 The relationship between left ventricular enddiastolic pressure (LVEDP) and left ventricular stroke work index (LVSW). Symbols same as in Fig. 1. A significant negative correlation is observed in both groups.

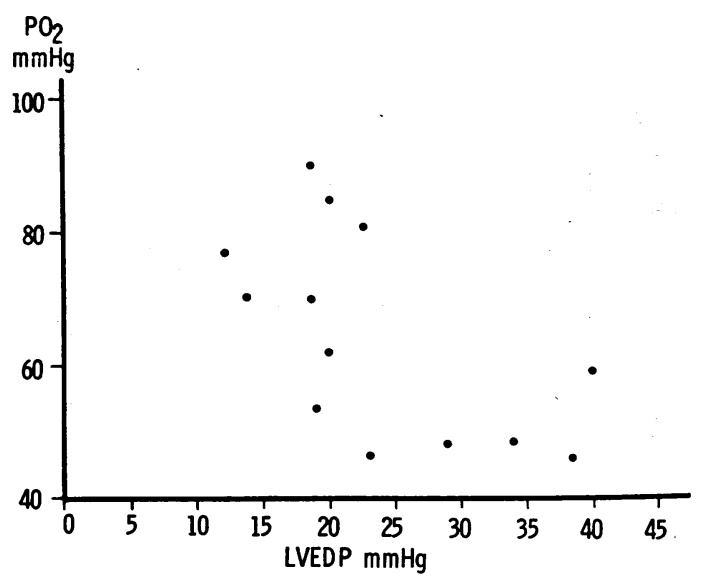

FIGURE 5 The relationship between left ventricular enddiastolic pressure and arterial oxygen tension $\left(\mathrm{PO}_{2}\right)(r=$ -0.59 ).

of the CVP may be of some value in detecting the presence of an elevated LVEDP, but it is not a dependable guide to the magnitude of the increase in left ventricular filling pressure.

Changes in CVP during volume expansion have previously been shown to serve as a fairly accurate reflection of changes in LVEDP in myocardial infarction shock (35). This relationship might not hold in the absence of shock, however, if left ventricular compliance were reduced. In the present series RAP was better correlated with LVEDP in shock than in the nonshock group. If a high LVEDP in patients with a nearly normal RAP is indicative of reduced left ventricular distensibility, it is possible that the RAP might actually be a more reliable guide to chamber dilatation.

The low arterial oxygen tension observed in acute myocardial infarction has been subjected to extensive study $(45,46)$. Although it is likely that arterial hypoxemia is of multiple etiologies in these patients, the significant negative correlation noted between $\mathrm{PO}_{2}{ }^{\circ}$ and LVEDP indicates that pulmonary venous hypertension is an important contributing factor. Since the high LVEDP often was not accompanied by signs of pulmonary congestion, these observations may help to explain the dilemma of other investigators who have observed hypoxemia in the absence of clinical signs of left ventricular failure (47).

\section{ACKNOWLEDGMENTS}

The authors are grateful to Doctors John Finnegan and Robert Kelley, who provided the opportunity for studies to be performed at Providence Hospital: Doctors Ibrahim Khatri and Martin Broder participated in some of the clinical studies, and Miss Eleanor Garlisi; R.N., and Mrs. Sally Shaughnessy, R.N., provided valuable technical assistance.

This investigation was supported in part by U. S. Public Health Service Research Grant HE 09785 from the National Heart and Lung Institute. 


\section{REFERENCES}

1. Fowler, N. O. 1968. Physical signs in acute myocardial infarction and its complications. Progr. Cardiovasc. Dis. 10: 287.

2. Freis, E. D., H. W. Schnaper, R. L. Johnson, and G. E. Schreiner. 1952. Hemodynamic alterations in acute myocardial infarction. I. Cardiac output, mean arterial pressure, total peripheral resistance, "central" and total blood volumes, venous pressure and average circulation time. J. Clin. Invest. 31: 131.

3. Gilbert, R. P., M. Goldberg, and J. Griffin. 1954. Circulatory changes in acute myocardial infarction. Circulation. 9: 847 .

4. Gammill, J. F., J. J. Applegarth, C. E. Reed, J. D. Fernald, and A. J. Antenucci. 1955. Hemodynamic changes following acute myocardial infarction using the dye injection method for cardiac output determination. Ann. Intern. Med. 43: 100.

¿. Broch, O. J., S. Humerfelt, J. Haarstad, and J. R. Myhre. 1959. Hemodynamic studies in acute myocardial infarction. Amer. Heart J. 57: 522.

6. Fluck, D. C., P. A. Valentine, B. Treister, B. Higgs, D. N. Reid, R. E. Steiner, and J. P. D. Mounsey. 1967. Right heart pressures in acute myocardial infarction. Brit. Heart J. 29: 748

7. Lassers, B. W., M. George, J. L. Anderton, M. R. Higgins, and T. Philip. 1970. Left ventricular failure in acute myocardial infarction. Amer. J. Cardiol. 25: 511.

8. Harrison, T. R. 1965 . Some unanswered questions concerning enlargement and failure of the heart. Amer. Heart J. 69: 100.

9. Weissler, A. M., W. S. Harris, and C. D. Schoenfeld. 1969. Bedside technics for the evaluation of ventricular function in man. Amer. J. Cardiol. 23: 577.

10. Kirby, B. J., M. W. McNichol, and A. E. Tattersfield. 1968. Left ventricular pressures in two patients with myocardial infarction. Lancet. 2: 944.

11. Nixon, P. G. F. 1968. Pulmonary edema with low left ventricular diastolic pressure in acute myocardial infarction. Lancet. 1: 146.

12. Shillingord, J. P., and M. Thomas. 1967. Cardiovascular and pulmonary changes in patients with myocardial infarction treated in an intensive care and research unit. Amer. J. Cardiol. 20: 484.

13. Weil, M. H., and H. Shubin. 1968. Shock following acute myocardial infarction; current understanding of hemo. dynamic mechanisms. Progr. Cardiovasc. Dis. 11: 1.

14. Smith, H. J., A. Oriol, J. Morch, and M. McGregor. 1967. Hemodynamic studies in cardiogenic shock. Treatment with isoproterenol and metaraminol. Circulation. 35: 1084.

15. Parmley, W. W., G. Glick, and E. H. Sonnenblick. 1968. Cardiovascular effects of glucagon in man. N. Engl. J. Med. 279: 12.

16. Soroff, H. S., W. C. Birtwell, F. Giron, U. Ruiz, A Nishimura, M. Many, M. El-Zawahry, and R. A. Deterling, Jr. 1969. Treatment of power failure by means of mechanical assistance. Circulation. 40(Suppl. IV) : 292.

17. Lillehei, C. W., A. J. Lande, W. R. Rassman, S. Tanaka, and J. H. Bloch. 1969. Surgical management of myocardial infarction. Some promising concepts utilizing revascularization, mechanical circulatory assistance, operative treatment of severe complications, and cardiac replacement. Circulation. 40 (Suppl. IV) : 315.
18. Editorial. 1968. Left ventricular function in acute myocardial infarction. Lancet. 2: 159.

19. Cohn, J. N., I. M. Khatri, and P. Hamosh. 1970. Bedside catheterization of the left ventricle. Amer. J. Cardiol. 25: 66 .

20. Braunwald, E., E. C. Brockenbrough, C. J. Frahm, and J. Ross, Jr. 1962. Left atrial and left ventricular pressures in subjects without cardiovascular disease. Observations in eighteen patients by transseptal left heart catheterization. Circulation. 24: 267.

21. Mintz, S. S., and L. N. Katz. 1947. Recent myocardial infarction. An analysis of five hundred and seventy-two cases. Arch. Intern. Med. 80: 205.

22. American Heart Association Committee on Anticoagulants. 1954. Myocardial Infarction. Grune \& Stratton, Inc., New York. 129.

23. Sampson, J. J., and J. C. Hutchinson. 1967. Heart failure in myocardial infarction. Progr. Cardiovasc. Dis. 10: 1.

24. Braunwald, E., and J. Ross, Jr. 1963. Ventricular end diastolic pressure. Amer. J. Med. 34: 147.

25. Linhart, J. W., F. J. Hildner, S. S. Barold, J. W. Lister, and P. Samet. 1969. Left heart hemodynamics during angina pectoris induced by atrial pacing. Circulation. 40: 483.

26. Weisse, A. B., R. S. Saffa, G. E. Levinson, W. W. Jacobson, Jr., and T. J. Regan. 1970. Left ventricular function during the early and late stages of scar formation following experimental myocardial infarction. Amer. Heart J. 79: 370.

27. Yu, P. N. 1969. Pulmonary Blood Volume in Health and Disease. Lea and Febiger, Philadelphia, Pa. 91.

28. Permutt, S., P. Caldini, A. Maseri, W. H. Palmer, T. Sasamori, and K. Zierler. 1969. Recruitment vs. distensibility in the pulmonary vascular bed. In The Pulmonary Circulation and Interstitial Space. A. P. Fishman and H. H. Hecht, editors. University of Chicago Press, Chicago, Ill. 175.

29. Gazes, P. C., J. A. Richardson, and E. F. Woods. 1959. Plasma catechol amine concentrations in myocardial infarction and angina pectoris. Circulation 19: 657.

30. Herman, M. V., and R. Gorlin. 1969. Implications of left ventricular asynergy. Amer. J. Cardiol. 23: 538.

31. Gunnar, R. M., H. S. Loeb, R. J. Pietras, and J. R. Tobin. 1968. Hemodynamic measurements in a coronary care unit. Progr. Cardiovasc. Dis. 11: 29.

32. Cohn, J. N. 1967. Central venous pressure as a guide to volume expansion. Ann. Intern. Med. 66: 1283.

33. Cohn, J. N., F. E. Tristani, and I. M. Khatri. 1969. Studies in clinical shock and hypotension. VI. Relationship between left and right ventricular function. J. Clin. Invest. $48: 2008$.

34. Rushmer, R. F. 1969. Function of infarcting myocardium. Circulation. 50(Suppl. IV) : 168.

35. Reeves, T. J., L. L. Hefner, W. B. Jones, C. Coghlan, G. Prieto, and J. Carroll. 1960. The hemodynamic determinants of the rate of change in pressure in the left ventricle during isometric contraction. Amer. Heart J. 60: 745.

36. Cohn, J. N., and M. H. Luria. 1964. Studies in clinical shock and hypotension; the value of bedside hemodynamic observations. J: Amer. Med. Ass. 190: 891.

37. Cohn, J. N., M. H. Luria, R. C. Daddario, and F. E. Tristani. 1967. Studies in clinical shock and hypotension. V. Hemodynamic effects of dextran. Circulation. 35: 316. 
38. Gunnar, R. M., A. Cruz, J. Boswell, B. S. Co, R. J. Pietras, and J. R. Tobin, Jr. 1966. Myocardial infarction with shock: hemodynamic studies and results of therapy. Circulation. 33: 753.

39. Swan, H. J. C., R. Danzig, Y. Sukumalchantra, and H. Allen. 1969. Current status of treatment of power failure of the heart in acute myocardial infarction with drugs and blood volume replacement. Circulation. 40 (Suppl. IV) : 277

40. Laurent, D., C. Bolene-Williams, F. L. Williams, and L. N. Katz. 1956. Effects of heart rate on coronary flow and cardiac oxygen consumption. Amer. J. Physiol. 185: 355.

41. Agress, C. M., and M. J. Binder. 1957. Cardiogenic shock. Amer. Heart J. $54: 458$.

42. Cohn, J. N. 1967. Myocardial infarction shock revisited. Aner. Heart J. 74: 1.
43. Thrower, W. B., T. D. Darby, E. E. Aldinger, J. M. Tenny, and S. H. Westbrook. 1959. Studies of the relationship between sympatho-adrenal function, acid base derangements and ventricular contractile force. Surg. Forum. 10: 535 .

44. Guyton, A. C. 1966. Textbook of Medical Physiology. W. B. Saunders Company, Philadelphia, Pa. 290.

45. McKenzie, A. J., S. H. Taylor, D. C. Flenley, A. H. McDonald, H. P. Staunton, and K. W. Donald. 1964. Circulatory and respiratory studies in myocardial infarction and cardiogenic shock. Lancet. 2: 825.

46. Valentine, P. A., D. C. Fluck, J. P. D. Mounsey, D. N. Reid, J. P. Shillingford, and R. E. Steiner. 1966. Bloodgas changes after acute myocardial infarction. Lancet 2 : 837.

47. Valencia, A., and J. H. Burgess. 1969. Arterial hypoxemia following acute myocardial infarction. Circulation. 40: 641 . 